\title{
Research on Community Participation in Zhuhai Airshow Based on the Theory of Relative Deprivation
}

\author{
Yifeng Du \\ Zhuhai College of Jilin University \\ Zhuhai, China 519041
}

\begin{abstract}
This paper takes Zhuhai Air Show as an example to conduct in-depth research on community participation in large-scale festivals such as Zhuhai Air Show. The author makes exploration from the perspective of relative deprivation theory, studies the relative deprivation index formula to do calculation and quantitatively analyzes the relative deprivation of community residents. Finally, he draws relevant conclusions, and analyzes the application and enlightenment in reality.
\end{abstract}

Keywords-relative deprivation theory; Zhuhai air show; community participation

\section{INTRODUCTION}

Tourism is currently experiencing a rapid development in the global economy. As an important part of the tourism industry, festival activities not only enhance the attraction of the host place, but also effectively promote local economic growth. Community participation is an important part of the sustainable development of festival activities. Large-scale festival activities can enhance the pride and identity of local residents. Their strong support and active participation have laid a solid social foundation for the success of the event. But at the same time, with the booming activities, the income of community residents has become more diverse. The gap between the rich and the poor has gradually widened, the phenomenon of social injustice has become more prominent, and the original social class has also changed. In response, some people will have a strong sense of imbalance. They perceive relative deprivation, and therefore, it is easy to trigger group conflicts and negative impact on the development of event activities will occur accordingly.

In view of this situation, based on the in-depth study of the theory of domestic and international community participation in the festival activities and the theory of relative deprivation, the large-scale event, China International Aviation and Aerospace Exhibition (hereinafter referred to as Zhuhai Air Show), is regarded as the research object. Centering on the relative deprivation of residents of Haicheng Village, a village close to the air show, the author attempts to study their participation in large-scale events such as the air show.

\section{THE THEORETICAL BASIS OF RESEARCH--- A}

SUMMARY OF THE THEORY OF RELATIVE DEPRIVATION

The theory of relative deprivation originated in the 1940s. It can explain many social phenomena such as cluster behavior, social dissatisfaction and population migration, and is considered to be an important weapon of social science. It has been widely used in social psychology, psychology and other social science fields.

Deprivation is a sociological term. Chinese scholar Wang Ning (2007) has conducted an in-depth study and concluded that deprivation is divided into five dimensions: physical deprivation, economic deprivation, political deprivation, social deprivation and spiritual deprivation. Among them, "social deprivation" was first proposed by British scholar Townsend in 1979 to solve the problem of social poverty.

With the deepening of research, social deprivation is divided into absolute deprivation and relative deprivation. The relative deprivation was first mentioned by the famous American sociologist Stouffer in the book "American Soldiers" published in 1949. In his book, Stouffer paid special attention to the psychological situation of American soldiers during the Second World War. Soldiers who show dissatisfaction tend to be those who are promoted in a relatively fast speed. The reason is that these soldiers always regard those high-ranking elites in the military as their own reference groups so that they feel that they are always at a disadvantage by comparing various aspects (income, rights, prestige, etc.) and feel that they have been deprived, which leads them always to stay on the road to the ideal position, resulting in a series of dissatisfaction. From Stouffer's research, it can be seen that relative deprivation is a post-eventing concept that can be used to explain dissatisfaction in those societies, especially to explain the objective things that do not seem to produce dissatisfaction at the beginning.

The sociologist Merton (1957) systematically expounds the sense of relative deprivation in his famous sociological classic "Social Theory and Social Structure" in two chapters (Chapters 10 and 11). He pointed out that there must be a certain reference system for relative deprivation. Merton also pointed out in the study that because people may face multiple reference groups, they will have different perceptions. British sociologist Runciman (1966) used the perspective of economics in the book "Relative Deprivation and Social Justice" to study the inequality in society and redefine the sense of relative deprivation. He believes that the reference group is an important measure norm and a solid basis for subsequent quantitative research. He sums up the situation in which relative deprivation is felt: someone does not own $\mathrm{X}$; 
sees others have $\mathrm{X}$; expects to have $\mathrm{X}$; and this expectation is reasonable.

In 1969, Davis added the past experiences of people themselves on the basis of the reference group and he believes that it is one of the reasons for the relative deprivation. However, scholars in the study found that there are two cases in which the use of reference group theory does not explain well the reason for the relative deprivation: the one is the relative deprivation produced when people find that their own interests increase when compared with other people or other groups. The other situation is that people do not compare their own interests with other people or other groups but they have a relative sense of deprivation.

This paper combines the theoretical views of Stouffer (1949), Merton (1957), and Davies (1969). Relative deprivation can be used to explain the dissatisfaction in society. It is a post-event explanation concept. At the same time, it can explain the objective conditions that do not seem to produce dissatisfaction at the beginning. The "deprivation" in relative deprivation is the additional and special cost in the concept, and it is a "relative" social psychological experience. The relative deprivation requires two conditions. On the one hand, people must have a certain reference or reference group to compare; on the other hand, people compare with their past experiences.

\section{RESEARCH CASE AND CASE OVERVIEW}

The large-scale event "China International Aviation and Aerospace Exhibition", referred to as Zhuhai Airshow, is representative of the industry and is the only large-scale international aerospace expo approved by the State Council. The organizers are mainly composed of the Guangdong Provincial People's Government, the National Defense Science and Technology Industry Committee, CAAC, and the China Council for the Promotion of International Trade. As of 2017, Zhuhai Airshow has successfully held 11 consecutive sessions. This large-scale professional exhibition held every two years is a combination of professional industry exhibitions, trade, academic exchanges and ornamental flight shows. The 11 sessions have brought huge economic and social benefits to Zhuhai City, Guangdong Province and even the Pearl River Delta region. According to official statistics of Zhuhai Air Show, the number of professional visitors to the Zhuhai Air Show in 2016 reached 135,000, and the professional audience was 230,000 . The turnover of the exhibition reached 40 billion US dollars.

Haicheng Village is located in Jinwan District of the western urban area of Zhuhai City and it is close to Zhuhai Airport and Zhuhai Air Show Pavilion, including 8 natural villages of Tianxin, Genzhuyuan, Shangbiao, Zhengbiao, Yingbiao, Antang, Liantang and Baishigong. With a total area of 18 square kilometers, the village is the largest administrative village in Sanzao Town, Jinwan District. Haicheng Village was originally a fishing village with backward economic development. When the government built the Zhuhai New Airport in the 1990s, it acquired more than 20,000 mu of land in Haicheng Village, causing the villagers to have to move to the opposite side of the original land to rebuild the village. The villagers who lost large areas of land at that time not only had difficulty in re-employment, but also lived in poverty. Luckily, the village government actively developed economic construction, cultivated the employment skills of the villagers, increased the collective income of the village, and improved the living standards of the villagers. Thanks to the development of more than 20 years, the strong support of the Zhuhai government, coupled with the vigorous development of the air show, Haicheng Village has undergone a tremendous transformation, and the collective income of the village and villagers themselves has steadily increased. In recent years, the government has been increasing the infrastructure construction of Haicheng Village. The Haicheng Village government also hopes to replicate the successful experience of the air show economy, and attempts to use social subsidies to incite social investment to improve the income of residents and the collective income of the village.

\section{RESEARCH METHODS AND DATA SOURCES}

In order to gain a deeper understanding of the relative deprivation of residents in the large-scale event community, a month was used to conduct a special investigation and research on the residents of Haicheng Village, a radiation village of the air show. Since Haicheng Village has 8 natural villages under its jurisdiction, this survey used the method of judging sampling to select four villages according to the distance, namely Zhengbiao Village, Tianxin Village, Shangbiao Village and Antang Village. This interview interviewed a total of 28 local villagers. There were 7 interviewees respectively received in-depth interviews among the four villages of Zhengbiao Village, Tianxin Village, Shangbiao Village and Antang Village under the jurisdiction of Haicheng Village.

The data of this study are derived from the statistics of Haicheng Village Neighborhood Committee. By the end of 2015, the household registration population of Haicheng Village was 4092, a total of 1008 households; the temporary population was about 4,000 (foreign migrant workers). with reference to the temporary population for the past five years, the growth rate is about 300 people per year. The study was conducted by random sampling. Random sampling was used in the four village household registration tables provided by the village committee. Random sampling was conducted according to the household registration population of 1008 households. 560 households were selected as research objects and 560 questionnaires were distributed.

\section{RESEARCH DESIGN}

This study obtained relevant data through in-depth interviews and questionnaire surveys in the early stage. Firstly, based on the actual deprivation sense index of the study, the relative deprivation index of the four villages surveyed was calculated and compared, and then SPSS23.0 software was adopted to carry out differential analysis of relative deprivation. The 7 indicators, such as the relationship between the gender, age, education, monthly income and the exhibition, the time of local residence, and villages at different distances were carried out differences and LSD multiple analysis in the three dimensions of relative deprivation, namely horizontal relative 
deprivation, vertical relative deprivation, and fairness respectively.

\section{RELATIVE DEPRIVATION INDEX CALCULATION RESULTS AND DISCUSSION}

Doing calculation according to the relative deprivation index calculation formula constructed by Chinese scholars Wang Jian and Peng Jian (2014) in the research on the interactive development of tourism and community in the southwestern minority areas, the sub-item relative deprivation index and comprehensive relative deprivation index of 4 different villages under the jurisdiction of Haicheng Village on different indicators can be obtained. The results of the study show that there are significant differences in the different observation indicators and the comprehensive relative deprivation index among the residents of different villages. Judging from the calculation results, Tianxin Village, Zhengbiao Village and Shangbiao Village have different degrees of relative deprivation. Among them, the relative deprivation of Tianxin Village residents is the strongest and the relative deprivation index reaches 1.7, followed by Zhengbiao Village with the relative deprivation index of 1.26, and there is also a relative deprivation in the Shangbiao Village with the index of 0.697 . There is no relative deprivation in Antang Village.

On the whole, the relative deprivation index calculated by the formula is basically consistent with the actual situation of the villages under Haicheng Village and the interview results in the previous period. It also has a certain relationship with the geographical location of the villages visited and the surrounding areas. Tianxin Village is the closest to the air show pavilion in the geographical position, and the impact of the air show is most obvious. The location of the air show pavilion is just the place where the villagers produce and live before the early 90s. The villagers moved to the opposite side due to the government's land acquisition and construction of the new airport and the air show hall. The villagers who lost their land and tidal flats had to work outside the home or in other ways to make a living, and they lived strapped lives. Compared with the other villages and the previous lives of their own, they feel that life is not satisfying. Coupled with the strong dissatisfaction with the compensation for land acquisition, they have relative deprivation, which makes Tianxin Village a village that has the strongest relative deprivation among the counterparts under jurisdiction.

Although Zhengbiao Village is a little farther away from Air Show Hall compared with Tianxin Village, it is also within two kilometers. Therefore, the direct experience of the air show is also deep, and the villagers have experienced the same land acquisition and navigation hall construction as the Tianxin Village, so, they also expressed inner dissatisfaction in the interview. Although in the process of the development of the subsequent air shows, Zhengbiao Village gained some benefits due to the geographical convenience, for example, the government has repaired the roads, improved the living environment of the villagers, and newly established commercial blocks, moreover, the changes brought by the air show upgrade the local economy to a certain extent, and some villagers have benefited from the convenience of the air show, most villagers believe that this kind of interest is insignificant compared with the damage of their own long-term interests (such as losing land and being difficult to find employment), so that the feeling of relative deprivation is still pretty obvious.

In the development process, Shangbiao Village has similar experiences with Tianxin Village and Zhengbiao Village, but it is not so obvious compared with the above villages. Some villagers think that although the compensation for land acquisition is not reasonable, all of this has passed. Fortunately, life is good now. In addition, some villagers think that it is a matter of the previous generation. Too much entanglement of the past cannot solve the problem. The development of the air show has brought about tremendous changes in the life of the villagers in the Shangbiao village and it is a village that has benefited relatively more in the interviews. The villagers are more satisfied with the living environment. In addition, the treatment of the nearby road traffic is benefited by the villagers. The construction of the happy village has also improved the quality of life of the villagers. In terms of distance, Shangbiao Village is farther away from the exhibition hall, being relatively less affected compared with Tianxin Village and Zhengbiao Village. What's more, there are nearby Zhuhai Shuohong Circuit Board Co., Ltd. And Xiaoxing Spandex (Zhuhai) Co., Ltd., so the villagers do not have to go out far away to look for work and some villagers serve these two companies. Their income is relatively stable. The selfsufficiency reduces dissatisfaction.

In addition, from the data results, in the calculation of the relative deprivation index, the relative deprivation index of Antang Village is -0.216 , showing no relative deprivation, which is related to the real situation of Antang Village: Antang Village is at a distance from the Air Show Hall, more than 5 $\mathrm{km}$ range. Although during the airport construction period in the early 1990s, the villagers of Antang Village also experienced historical events such as airport land acquisition and air show development, the Zhuhai College of Jilin University, which was supported by the Zhuhai government in 2004, was located less than one kilometer away from Antang Village. This brought new vitality to Antang Village and made the villagers of Antang Village economically profitable. The Zhuhai College of Jilin University has been in development for 14 years and it has a good development trend. Now it has nearly 30,000 students and faculty members. The villagers have invested in the service industry, such as catering, accommodation, rental housing and other related industries, and benefited from it. The establishment of Zhuhai College of Jilin University has made local villagers' incomes better and their lives stable. In addition, Zhuhai College of Jilin University also provided a large number of jobs for the villagers such as security and cleaning. The villagers serve the school and feel that the income is relatively stable, so they tend to be satisfied with life: the villagers can be self-sufficient. Whether compared with the previous life, or other villages, they have comparative advantages. Relying on the operation benefits of Zhuhai College of Jilin University, the villagers of Antang Village have higher economic income than the other three villages. Therefore, no matter from the horizontal relative deprivation, the vertical relative deprivation and the concept of fairness, there is no relative deprivation in this village. 


\section{CONCLUSION}

A large number of practices and research have shown that after a festival is developed in a place, the industrial structure of the destination community will change, and the local social structure will undergo tremendous changes and adjustments. At the same time, the income sources of community residents have become more diversified, the gap between the rich and the poor has gradually increased, the phenomenon of social injustice has become more prominent, and the original social class has also altered (Wang Jian, Peng Jian, 2012). Under normal circumstances, community residents tend to be relatively weak in the development of festival activities, and are marginalized in the process of development often without fair treatment. Therefore, this kind of people will have a strong sense of imbalance. They perceive the relative deprivation and easily lead to group events, which will have a negative impact on the development of the festival activities. In some economically underdeveloped areas where the festival industry has become a local leading industry, the problems of relative deprivation brought about by the development of festival activities will be more serious. Therefore, it is necessary to pay attention to the relative deprivation of community residents, and to think deeply about the reasons of the problems and the way to solve them.

In view of the relative deprivation of community residents in Zhuhai Air Show, such as Tianxin Village, Zhengbiao Village and Shangbiao Village in the case, it is wise to actively construct a psychological counseling mechanism for the relative deprivation of community residents to weaken and eliminate their relative deprivation. On the one hand, this kind of psychological counseling mechanism should guide the community residents to select appropriate reference groups according to their respective conditions for comparison. On the other hand, it is necessary to explain the scientific nature and rationality of the current interest distribution system to the community residents through media and community announcements. It is necessary to educate community residents to abandon the wrong idea of egalitarianism, guide them to face reality and recognize differences. Meanwhile, community residents should be encouraged to make positive progress and improve their economic life through their own efforts to dispel the subjective feelings that are not in line with reality. In addition, when doing psychological counseling, it is necessary to formulate corresponding measures according to the different levels of needs of the community residents, not only to try to meet their material needs, but also to consider their spiritual needs in order to achieve better psychological counseling.

Community participation in large-scale festival activities is a necessity for the development of festival activities. The host process of large-scale festival activities will be affected by many aspects, especially the influence perception and attitude of local community residents, which will make differences for the development of festival activities. If the community residents show a positive attitude towards the festival activities, the activities will proceed smoothly as scheduled; if a negative attitude is presented, it will lead to the failure or delay of the activities, so the study of community participation in largescale festival from the perspective of community residents has important and far-reaching implications both in theory and in practice.

\section{REFERENCES}

[1] Wang Ning (2007). Relative Deprivation: From Horizontal to VerticalTaking the Experience of Urban Retired Elderly People in the Transformation of Medical Security System as an Example. Journal of Northwest Normal University: Social Science Edition, 44 (4) , 1925 。

[2] Wang Jian, Peng Jian (2014). Study on the Tourism Influence Perception and Participation Willingness of Residents in Tourist Destination Based on Structural Equations_- Taking the Zhangjiang Scenic Area as an Example. The Proceeding of China Tourism Academy, 66-75。

[3] Wang Jian, Peng Jian (2012) .The Context and Progress of Chinese and Foreign Community Participation in Tourism Research. Journal of the Central University for Nationalities (Philosophy and Social Sciences Edition) (3) , 133-141 